Revue d'histoire de l'Amérique française

REVUE D.HISTOIRE DE L'AMÉRIQUE FRANÇAISE

\title{
Mgr de Laval et le Conseil souverain 1659-1684
}

\section{Lucien Campeau}

Volume 27, numéro 3, décembre 1973

URI : https://id.erudit.org/iderudit/303281ar

DOI : https://doi.org/10.7202/303281ar

Aller au sommaire du numéro

Éditeur(s)

Institut d'histoire de l'Amérique française

ISSN

0035-2357 (imprimé)

1492-1383 (numérique)

Découvrir la revue

Citer cet article

Campeau, L. (1973). Mgr de Laval et le Conseil souverain 1659-1684. Revue

d'histoire de l'Amérique française, 27(3), 323-359.

https://doi.org/10.7202/303281ar d'utilisation que vous pouvez consulter en ligne.

https://apropos.erudit.org/fr/usagers/politique-dutilisation/ 


\title{
MGR DE LAVAL ET \\ LE CONSEIL SOUVERAIN \\ 1659-1684
}

\author{
Lucien Campeau \\ Département d'histoire \\ Université de Montréal
}

Le clergé, dans l'ancienne société française, est l'un des organismes directeurs de la collectivité chrétienne, régie par deux puissances, la puissance royale, la puissance ecclésiastique, toutes deux émanant de Dieu d'une manière différente et dirigeant le destin de la société humaine, la première vers un ordre historique et terrestre le mieux réussi possible, la seconde vers un ordre éternel et céleste le plus conforme possible à la nature spirituelle de l'homme. Le pouvoir royal n'est pas indifférent à la loi de Dieu, qui est le fondement ultime de la société humaine. C'est pourquoi il conforme ses lois et son administration aux suggestions de ceux qui ont reçu mission d'interpréter la loi de Dieu, les évêques. D'autre part, les évêques n'ont pas pouvoir direct sur la société terrestre comme telle, excepté dans les cas où le Roi leur confère une partie de la sienne. Ils ont besoin que le pouvoir royal organise et régisse la société d'une manière qui favorise le salut éternel des sujets. Deux pouvoirs, chacun indépendant de l'autre dans son domaine propre. Mais, en France, il est admis que le pouvoir royal a la priorité sur le pouvoir épiscopal, dans les domaines où les deux juridictions entrent légitimement en concurrence.

Depuis le Moyen âge, il y a aussi en France une doctrine politique des juristes, surtout recrutés dans la haute bourgeoisie. A leurs yeux, le pouvoir royal est un pouvoir laïque, c'est-à-dire exclusif de tout caractère sacerdotal ou clérical. En conséquence, le service du Roi est l'apanage propre des laïcs. Le Roi lui-même, ordinairement éduqué par des ecclésiastiques, voit son rôle en composition, non en opposition, avec la puissance sacerdotale; mais ses ministres le voient en opposition, non en composition, avec la même puissance. L'autorité royale, dans l'esprit du Roi, se situe au-delà de la distinction laïc-clerc; dans l'esprit des juristes, elle est une autorité laïque, en opposition avec l'autorité des évêques. Et ce qui sert à établir la suprématie royale dans

[323 ]

RHAF, vol. 27, no 3 (décembre 1973) 
la pensée du Roi est employé par les juristes à établir la suprématie des laïcs sur les clercs. Il n'est pas étonnant que le Roi choisisse des ecclésiastiques comme ses ministres ou comme membres de ses conseils. Hauts dignitaires ecclésiastiques, ils ne sont pas moins sujets du Roi et notables du royaume que les avocats ou les nobles. Mais les juristes grincent des dents, parce que pour eux toutes les dignités émanant de l'autorité royale devraient être réservées aux laïcs. Quand les magistrats de la Nouvelle-France opposent l'autorité royale à celle des ecclésiastiques, sachons bien que c'est leur propre autorité de laïcs qu'ils voudraient établir au-dessus de celle des autres, et non l'autorité que le Roi s'attribue à lui-même.

Sous l'ancien régime, plusieurs évêques ont été ministres (Richelieu, Mazarin, Fleury, etc.). Dans les Conseils, il y a toujours eu nombre d'ecclésiastiques. En Nouvelle-France, il n'y avait qu'un Conseil: rien de plus normal qu'il s'y trouvât un représentant ecclésiastique. C'est le contraire qui eût été anormal.

\section{Le premier Conseil}

L'établissement d'un Conseil, à Québec, remonte, comme on le sait, au 27 mars 1647. C'était un conseil de gestion et de surveillance du commerce, ce dernier ayant été cédé à la communauté des Habitants. Il était composé du gouverneur général, représentant le Roi et la compagnie, du supérieur des Jésuites, en attendant qu'il y eût un évêque, et de Maisonneuve, qui représentait les intérêts de la Société de Montréal. Ce Conseil fut réformé et augmenté en 1648. L'administration de Lauson, coïncidant avec le déclin de la traite des fourrures à cause des guerres iroquoises, suscita beaucoup de plaintes dans la colonie et en France. Les Jésuites, trouvant ces chicanes nuisibles à l'évangélisation, demandèrent au Roi la permission de ne plus assister au Conseil, ce que le monarque leur accorda. Le 7 mars 1657, lors de la réorganisation du Conseil de Québec, il ne fut plus question d'une représentation cléricale dans cet organisme. Ainsi, M. de Queylus, arrivant au pays comme vicaire général de l'archevêque de Rouen, n'y eut pas de place. Il en fut de même pour Mgr de Laval à son arrivée, même si le règlement de 1647 lui en prévoyait une; on fonctionnait selon l'arrêt de restauration de 1657.

Le gouverneur $\mathrm{Du}$ Bois d'Avaugour, voulant utiliser l'expérience des ecclésiastiques, força en 1661 le supérieur des Jésuites, le $\mathrm{P}$. Jérôme Lalemant, à faire partie du Conseil. Voici l'extrait du Journal des Jésuites qui en fait foi: 
Le premier [octobre 1661], quelque résistance que nous y puissions apporter, Monsieur le Gouverneur d'Avaugour nous obligea d'assister au Conseil et, me l'ayant commandé plusieurs fois par toute l'authorité qu'il avoit, sans vouloir recevoir d'excuse, m'envoya sur le temps de le tenir son secrétaire pour m'y conduire. Où estant arrivé, il m'y establit et, à mon défaut, telle personne des nostres que je voudrois ${ }^{1}$.

La situation du Père Lalemant était délicate, les raisons qui avaient fait renoncer à cette participation étant toujours valides. Pour atténuer la représentation jésuite, le supérieur délégua le Père Ragueneau. Et voici un extrait de lettre de M. d'Avaugour au prince de Condé, qui confirme cette disposition:

J'ay mis à la tête d'un conseil général pour le cervisse du roy et le bien du peis le révérend père Ragnaust, lequel a l'honneur d'estre connu de Vostre Altesse et avec trois austres, tous les jours, délibère des afaires publiques; par son mérite, j'ay creu ne pouvoir rien de mieus. Sy l'ocasion s'en ofre, je suplie Vostre Altesse d'octoriser cette conduite et d'estre tout persuadé que les Jésuites qui ont plus travaié pour le peis $(\text { sic })^{2}$.

Tout cela pose cependant un petit problème historique, qui a été diversement traité par les historiens. Mgr Gosselin ne touche le sujet que dans une note, en passant: "Dans l'automne de 1661, il pria le supérieur des Jésuites d'assister au Conseil. L'Evêque y était déjà de droit; et ce droit fut confirmé par un nouvel arrêt du conseil d'Etat, en date du 24 mai 1661, enregistré au conseil de Québec le 27 septembre de la même année." 3 M. Lanctot, de son côté, raconte l'incident de cette manière: "Mécontent sans doute des suggestions de 'n'ordonner rien sans la participation' de Mgr de Laval, le gouverneur, au lieu d'appeler l'évêque au Conseil, oblige 'd'y assister', le $1^{\text {er }}$ octobre, malgré sa 'résistance' le supérieur des Jésuites, le P. Jérôme Lalemant. Mais celui-ci, après son premier contact avec le gouverneur, s'empresse de se dérober à cette fonction. Reconnaissant le zèle et l'expérience des missionnaires, d'Avaugour met alors 'à la teste' du Conseil l'entreprenant et persuasif P. Ragueneau, croyant 'ne pouvoir faire rien de mieux', écrit-il au prince de Condé, en le sollicitant d'autoriser cette "conduite'." 4 Mgr Gosselin semble avoir tort en ce que Mgr de Laval ne fut pas membre du Conseil

${ }^{1}$ Laverdière et Casgrain, Le Journal des Jésuites (JJ) (Montréal, 1892), 302-303.

2 Camille de Rochemonteix, Les Jésuites et la Nouvelle-France au 17 e siècle (3 vol., Paris, 1895-1896), II : 527.

3 Auguste Gosselin, Vie de Mgr de Laval, premier évêque de Québec et apôtre du Canada, 1622-1708 (2 vol., Québec, 1890), I: 297. I: 318 .

4 Gustave Lanctot, Histoire du Canada (3 vol., Montréal, 1960-1964), 
dès son arrivée. Mais il a raison de signaler que l'arrêt du 24 mai 1661 donne à l'évêque pleine entrée au Conseil. Le silence de la lettre de D'Avaugour à propos de l'évêque ne signifie pas l'exclusion du prélat. L'évêque n'est pas nommé au Conseil; il en est membre ex officio, tout comme le gouverneur. Le Père Ragueneau se trouve être le premier conseiller parmi ceux qui sont nommés. C'est donc Mgr Gosselin qui a raison, et non M. Lanctot. Il n'est pas concevable que le gouverneur, qui a été précédé lui-même par l'arrêt royal concernant Mgr de Laval, qui l'a trouvé déjà enregistré depuis le 27 septembre, ait refusé au prélat l'entrée au Conseil; d'autant moins que la séance d'enregistrement est celle même où le fonctionnaire prend possession de son poste. Mgr de Laval est donc entré au Conseil le 27 septembre 1661.

\section{Fondation $d u$ Conseil souverain}

Lors du voyage de Mgr de Laval en France en 1662-1663, on sait que la colonie est passée directement sous le pouvoir royal et que le Roi y a institué un Conseil souverain, c'est-à-dire une cour de justice analogue aux parlements des principales villes de France ${ }^{5}$. Il suffit de lire les lettres patentes d'institution de ce parlement ou Conseil, pour se rendre compte du rôle qui s'y trouve assigné à Mgr de Laval. Il y apparaît comme un membre-né, c'est-à-dire comme celui que sa fonction dans la société, et pas seulement la nomination personnelle, désigne comme un membre naturel et perpétuel de cette institution au même titre que le lieutenant du Roi ou gouverneur.

Par un édit du mois d'avril 1663, Louis XIV érige donc un "Conseil Souverain ... séant en notre dite ville de Québec", lequel "Nous voulons être composé de nos chers et bien-aimés les sieurs de Mésy, gouverneur, représentant notre personne, de Laval, évêque de Pétrée, ou du premier ecclésiastique qui y sera, et cinq autres qu'ils nommeront et choisiront conjointement et de concert, et d'un nôtre procureur audit Conseil Souverain". Les cinq conseillers seront changés ou continués tous les ans "par les dits gouverneur, évêque ou premier ecclésiastique qui y sera". Le Conseil entendra les causes civiles et criminelles, règlera la dépense des deniers publics, disposera de la traite et de tout le commerce, de même que des affaires de police générales et particulières du pays, instituant des tribunaux inférieurs, des

5 Parlement modeste, qui a cependant les attributions de ceux de France et quelques autres en plus et qui est "souverain", c'est-à-dire subordonné à nulle autre institution de même nature. 
greffiers, des notaires, des tabellions, sergents et autres officiers de justice, selon le besoin. Pour la conservation des archives, le gouverneur et l'évêque ou premier ecclésiastique nommeront un secrétaire-greffier, révocable selon leur bon jugement. Suit l'ordre au gouverneur et à l'évêque, ou premier ecclésiastique, d'exécuter la teneur de l'édit, en nommant les conseillers, le procureur et le greffier, et en faisant enregistrer et publier l'édit lui-même par ce Conseil ${ }^{6}$.

Arrivés tous deux à Québec, le gouverneur Augustin de Saffray de Mésy et Mgr François de Laval constituèrent le Conseil en conformité avec le commandement royal. Il est bien sûr que le vicaire apostolique eut l'influence prédominante dans le choix des conseillers, parce qu'il était alors seul à connaître les habitants de la colonie. Furent nommés conseillers, par ordre d'ancienneté:

Louis Rouer, sieur de Villeray,

Jean Juchereau, sieur de La Ferté,

Denis-Joseph Ruette d'Auteuil, sieur de Monceaux,

Charles Le Gardeur, sieur de Tilly,

Mathieu Damours, sieur des Chauffours.

Le procureur du Roi fut Jean Bourdon, sieur de Saint-Jean et Saint-François, et le greffier ou secrétaire du Conseil fut JeanBaptiste Peuvret de Mesnu.

La première séance du Conseil se tint le 18 septembre $1663^{7}$. L'édit d'établissement et les nominations y furent enregistrées, de même que les actes de transfert de la colonie de la compagnie de la Nouvelle-France au Roi, la commission du gouverneur Mésy et celle de Gaudais-Dupont, commissaire royal venu enquêter sur l'état du pays. Les trois personnages principaux du Conseil, à ce moment, par ordre de préséance, sont M. de Mésy, lieutenant du Roi, Mgr de Laval, vicaire apostolique, et M. Gaudais-Dupont, commissaire.

\section{Conflit Mésy-Laval}

Le danger constant du Conseil souverain, dans une colonie aussi éloignée de la France, était qu'il devînt un instrument de

${ }^{6}$ Edits, Ordonnances royaux, Déclarations et Arrêts du Conseil d'Etat du Roi concernant le Canada (Québec, 1854), 37-39.

7 Jugements et Délibérations du Conseil Souverain de la NouvelleFrance (JDCS) (6 vol., Québec, 1885-1891), I: 1-3. 
despotisme entre les mains du gouverneur. La chose était même arrivée récemment. D'Avaugour avait cassé le précédent conseil et il l'avait recomposé d'hommes de son choix, dérogeant à l'arrêt de 1657. Ensuite, il avait pris seul, sans même le consulter, les décisions les plus graves au sujet de la traite de Tadoussac. Elles durent être annulées par le Conseil souverain, le 2 octobre $1663^{8}$. Ce point des révocations de conseillers sera l'un de ceux auxquels le Roi sera le plus sensible et qu'il considérera comme le plus grave dans la conduite des gouverneurs. Il importait donc de ne pas abandonner les nominations au caprice de ces derniers, dans l'hypothèse où le Roi ne les faisait pas lui-même. C'est pourquoi les lettres patentes du Conseil souverain imposaient qu'elles fussent faites conjointement et en plein accord par le gouverneur et par l'évêque. Ne détenant lui-même aucune autorité ou puissance politiques, le prélat ne peut être tenté de les employer pour plier les conseillers à ses volontés, comme nous verrons souvent les gouverneurs le faire. Quant à son autorité ecclésiastique, elle ne s'exerce pas dans le domaine qui est celui du Conseil; et ni le Roi ni aucun légiste n'admettra jamais qu'elle puisse être utilisée pour forcer la volonté des conseillers dans l'exercice de leur fonction. En fait, on ne verra jamais un évêque de Québec le tenter. La nécessité du consentement du prélat à la nomination ou à la destitution des conseillers est une garantie de l'indépendance et de la liberté du Conseil.

On ne sera pas lent à éprouver le bien-fondé de cette précaution. Les difficultés auraient commencé, dès la fin de l'année 1663, sur la question des gages du gouverneur. Mésy, d'après un témoin hostile, aurait demandé qu'ils fussent de 5000 livres supérieurs à ceux de ses prédécesseurs. Des procès-verbaux du Conseil, toutefois, il ne ressort pas que ses exigences aient été si fortes et qu'elles aient allumé la querelle ${ }^{9}$. Il s'agirait plutôt, si nous lisons bien une ordonnance de Mésy, du 4 février 1664, d'une divergence de vue entre les conseillers et le gouverneur sur la manière d'administrer la justice ${ }^{\mathbf{1 0}}$. Certains membres du Conseil,

8 JDCS, I: $10-12$.

9 JDCS, I: 67-78. Sa commission lui enjoignant de se régler, à ce sujet, sur ce qu'avaient reçu les trois gouverneurs précédents, Mésy laissa au Conseil de décider lequel servirait d'exemple. Le Conseil choisit M. d'Argenson. Mésy demandait en outre d'être payé en monnaie de France, d'un tiers plus précieuse que la monnaie du Canada. Les conseillers offrirent $7000 \mathrm{lt}$ en monnaie de France; quant au reste, $6050 \mathrm{lt}$, il serait payé en monnaie du pays. Cet arrangement faisait perdre à Mésy quelque 1500 livres, monnaie de France. Il perdait aussi sur les soldes de quinze nouveaux soldats, payés en argent du pays.

10 P.-G. Roy, Ordonnances, Commissions, etc. etc. des Gouverneurs et Intendants de la Nouvelle-France, 1639-1706 (Beauceville, 1924), I: 16-17. 
continuant peut-être une pratique habituelle dans cette société quasi-familiale, agissaient à titre privé comme arbitres des différends entre habitants. Ils recevaient des requêtes et y répondaient, probablement pour éviter les frais. L'évêque a peut-être agi de la sorte. Villeray, premier conseiller, habile en jurisprudence, ainsi que Bourdon, le procureur, ont dû le faire. Le gouverneur prit ombrage de ces initiatives, puisqu'il les interdit aux conseillers et aux habitants sous peine d'une amende de cent livres, ordonnant que toute requête lui fût personnellement adressée, pour qu'il y répondît lui-même, si le Roi était intéressé, ou par le Conseil, en matière de police ou de justice. Mésy publia l'ordonnance sans la participation du Conseil, qui ne manqua pas d'en être froissé. La conduite des conseillers était jusqu'à un certain point plausible, puisque le Roi donnera plus tard à Talon le pouvoir de rendre une justice expéditive semblable. Mais le gouverneur était surtout fâché de voir les causes échapper à sa connaissance et à son autorité ${ }^{11}$.

Le Conseil se trouva divisé en deux parties égales. D'un côté, Villeray, D'Auteuil et Jean Bourdon, avec lesquels l'évêque semble s'être rangé; de l'autre, Le Gardeur de Tilly, Juchereau de la Ferté et Damours, qui, sans appuyer le gouverneur, ne lui faisaient pas opposition. Le 8 février 1664, le gouverneur absent, les conseillers donnèrent l'ordre d'afficher à la porte de l'église l'édit d'établissement du Conseil et l'acte de nomination des conseillers ${ }^{12}$. C'était une réplique à Mésy, qui prononça contre Villeray, D'Auteuil et Bourdon un ordre d'exclusion du Conseil. Le 13 février, le gouverneur envoya son secrétaire, Angoville, porter à l'assemblée un écrit accusant Mgr de Laval de former avec les trois opposants une cabale pour dominer le Conseil et l'invitant à procéder avec lui à la nomination de leurs successeurs. Il exigeait l'enregistrement de ce billet. L'évêque fit opposition, tout en demandant une copie du document pour le greffe. Angoville, sur l'ordre de son maître, repartit avec la sommation pour la faire afficher. Elle sera en fait enregistrée le 16 février. A la suite, Mgr de Laval enregistrera encore une protestation, à l'effet qu'il ne pouvait consentir à l'interdiction des conseillers ni procéder à leur remplacement tant qu'ils n'auraient pas été

${ }^{11}$ La Tour [Mémoires sur la vie de Mgr de Laval (Cologne, 1761), 84] fait de M. de Mézy un partisan de la vente de l'eau-de-vie aux Indiens et explique surtout par là son opposition à l'évêque. Mais cet auteur, très utile, a besoin d'être vérifié. Sur ce point de l'eau-de-vie, je ne vois pas de confirmation suffisante. Plus loin (p. 119-121), l'auteur commet des erreurs plus évidentes et raconte des histoires peu vraisemblables.

12 JDCS, I : 119. 
convaincus par un jugement légitime des crimes dont on les accusait ${ }^{13}$.

Devant ce refus, Mésy voulut au moins faire nommer un substitut au procureur général Jean Bourdon, nécessaire à la marche du Conseil. Mgr de Laval laissa faire, tout en protestant que cette nomination ne devait pas porter préjudice au bon droit du procureur. Cela avait lieu le 5 mars $1664^{14}$. Cinq jours plus tard, le gouverneur nomma seul Louis-Théandre Chartier de Lotbinière, qui fut reçu le 12 mars, le prélat protestant de nouveau ${ }^{15}$. Le Conseil fonctionna ainsi durant le mois de mars, Mgr de Laval s'opposant encore, le 18, à l'ouverture des papiers de Péronne Dumesnil, l'affaire étant trop importante pour un Conseil incomplet ${ }^{16}$. Le gouverneur avait eu le temps de se calmer. Le 26 mars, il biffa le nom de Ruette d'Auteuil de son ordonnance du 13 février, renonçant ainsi aux accusations portées contre ce conseiller et lui permettant d'assister aux séances ${ }^{17}$. Le 16 avril, il faisait la même chose pour les deux autres, Villeray et Bourdon, qui rentrèrent aussi, Lotbinière donnant sa démission comme substitut du procureur ${ }^{18}$.

Le champion de la liberté du Conseil était Rouer de Villeray, premier conseiller, qui pour ce motif sera la bête noire de tous les gouverneurs jusqu'à la fin du premier terme de Frontenac. M. Lanctot a écrit plutôt un pamphlet qu'une histoire à propos de Villeray ${ }^{19}$. Celui-ci a sauvé alors et plusieurs fois par la suite la dignité du Conseil ${ }^{20}$. Les relations demeurèrent tendues entre lui et Mésy, car il avait qualifié d'impertinente l'ordonnance d'interdiction des trois conseillers ${ }^{21}$. Le 13 août 1664 , le gouverneur le rabroua en plein conseil ${ }^{22}$. Villeray décida de passer en France pour se défendre des accusations lancées contre lui : il partit le 30 août ${ }^{23}$. Je souligne la date, parce que M. Lanctot le fait participer à la querelle suivante, qui eut lieu en septembre ${ }^{24}$.

13 JDCS, I: 121, of 145; Roy, Ordonnances, Commissions ..., 1: 18-20.

14 JDCS, I : 128.

15 JDCS, I : 129.

16 JDCS, I : 136.

17 JDCS, I : 145.

18 JDCS, I: 170.

19 Lanctot, Histoire du Canada, 1 : 295, 324 ; 2 : 17, 28-32.

20 On peut lire avec avantage le long article de M. P.-G. Roy sur Villeray, dans Bulletin des Recherches Historiques (BRH) 26 (1920): 33-52, 65-77, 97-111, 129-145, 161-176; et aussi, à Rouer de Villeray, celui de M. Bernard Weilbrenner, dans le Dictionnaire biographique du Canada (DBC), [Québec-Toronto, 1965, éd. Laurentienne], I: 593-596.

21 JDCS, I: 271.

22 JDCS, I: 255.

$23 \mathrm{JJ}, 328$.

24 Lanctot, Histoire du Canada, 2: 31. 
On avait tardé jusque-là à faire élire un syndic, ou représentant des habitants, pour Québec. Mésy y tenait beaucoup, pour avoir un interlocuteur populaire qui lui apporterait, comme au gouverneur ou au président du Conseil, les doléances des habitants. Les conseillers étaient moins pressés. Le 28 juillet, le Conseil avait ordonné la tenue d'une assemblée dans ce but ${ }^{25}$. L'élection eut lieu le 3 août ${ }^{26}$. Claude Charron fut choisi. Comme il était marchand et que les intérêts des marchands étaient contraires à ceux des habitants, il y eut de nombreuses protestations. $\mathrm{Au}$ surplus, Charron était un partisan du gouverneur et un adversaire de Villeray. En septembre, le Conseil, par la voix de Charles de Lauson-Charny, demanda au gouverneur de presser Charron de démissionner, plutôt que de lui infliger la honte d'une destitution. Mgr de Laval était alors malade et se faisait remplacer par son vicaire général. Remarquer que le vicaire apostolique, d'après les lettres d'institution du Conseil, avait ainsi le pouvoir de se faire remplacer, tandis que le gouverneur ne l'avait pas. Mésy acquiesça aux désirs du Conseil et Charron démissionna. Les conseillers convoquèrent une nouvelle assemblée, qui fut trop peu nombreuse et ne permit pas une élection. S'impatientant, Mésy convoqua lui-même par billet un certain nombre de personnes, auxquelles il n'avait pas dit le sujet de la réunion, pour une nouvelle élection, qui s'arrêta sur le nom de Jean Lemire, charpentier, le 14 septembre 1664. Le gouverneur justifiait son procédé par le besoin d'échapper aux intrigues de la cabale du Conseil, qui terrorisait les habitants ${ }^{27}$. Le nouveau syndic devait prêter serment devant le Conseil. M. de Lauson-

25 JDCS, I: 245-246.

26 JDCS, I: 250. L'assemblée, réunissant vingt-trois notables, se fit au Conseil, le 3 août, devant quatre conseillers et le procureur. Il semble bien que les conseillers, probablement par inexpérience, aient outrepassé leur droit en convoquant cette assemblée. C'était plutôt le rôle du gouverneur.

27 JDCS, I: 278-280. En fait, le Conseil se contredisait, parce que luimême avait présidé l'élection de Charron et reçu son serment. Le vicaire général, Lauson-Charny, semble s'être fait le porte-parole du mécontentement populaire, entraînant l'adhésion des autres conseillers. Après le deuxième échec, Mésy prit l'affaire en main, ce qui semble avoir été son droit, la convocation d'assemblées n'appartenant pas aux conseillers, mais son procédé gâta les choses, envenimées encore par l'obstination du vicaire général et de ses partisans. Quelles étaient les vraies motivations des parties en cause ? Il est difficile de le dire. S'il s'agit d'une coterie bourgeoise et marchande, opposée au gouverneur, pourquoi a-t-elle élu, puis rejeté Charron? Si la cabale était plutôt d'inspiration populaire, pourquoi son opposition au charpentier Lemire? Sur le plan religieux, on n'a aucune raison de penser que Charron ou Lemire aient été inacceptables. Une passion déraisonnable et incontrôlée, des deux côtés, paraît être la source du malentendu. 
Charny, Jean Juchereau de La Ferté et Denis Ruette d'Auteuil s'y opposèrent, à cause de l'illégalité de l'élection. De l'autre côté, il y avait le gouverneur, Le Gardeur de Tilly et probablement aussi Jean Bourdon, qui avait dit ne pas avoir d'objection à ce syndic. Restait le conseiller Damours, qui avait dû sortir de la chambre du Conseil, parce qu'il était le beau-frère de Jean Lemire. L'assemblée était donc divisée en deux parties égales, sans majorité, et Lauson-Charny, La Ferté et Ruette d'Auteuil insistaient fort pour qu'on suivît leur avis. Mésy convoqua Lemire et lui fit prêter serment, mais Lauson-Charny, La Ferté et D'Auteuil voulurent faire enregistrer leur opposition, qui ne démordait pas. Dans ces discussions revinrent naturellement les accusations de cabale opposée au gouverneur et à l'administration. Il faut noter que Lauson-Charny et Juchereau étaient beaux-frères ; ayant tous deux épousé des filles de Robert Giffart, mais D'Auteuil n'était parent ni de l'un ni de l'autre ${ }^{28}$.

Devant cette résistance des trois membres du Conseil, Saffray de Mésy, qui devait avoir médité son plan depuis longtemps, déclara que, puisqu'il y avait déjà un an que le Conseil avait été constitué (18 septembre) et que les conseillers étaient rééligibles chaque année, les sieurs de Villeray, de La Ferté, d'Auteuil et Bourdon n'étaient plus désormais membres du Conseil, mais que les sieurs de Tilly et Damours étaient continués comme conseillers. Bourdon, qui ne semblait pas devoir encourir à ce moment la colère du gouverneur, protesta qu'il ne se tenait pas pour démis. Mésy le fit sortir par force de la salle ${ }^{29}$. En fait, le gouverneur avait multiplié les accusations contre Villeray et Bourdon, en même temps que contre l'évêque et les jésuites. Les deux membres du Conseil étaient obligés de porter leur cause devant le Roi. En les congédiant, Mésy prévenait la sentence et se faisait justice à lui-même.

Il est fort possible que Mgr de Laval ait jugé que son substitut, M. de Lauson-Charny, avait agi au Conseil avec plus de vivacité et de parti pris qu'il ne l'aurait fait lui-même; dans la querelle précédente, l'évêque se contentait de protester et de donner ses raisons, mais sans empêcher le gouverneur de faire ce qu'il voulait. Ce qui le laisserait croire, c'est que le prélat, pendant les années qui vont suivre, ne se fera plus remplacer au Conseil par un autre prêtre; quand il ne pourra pas y aller, il s'absentera simplement, malgré le droit qu'il avait de se faire représenter. Un autre indice que l'opposition des deux beaux-

28 Voir la notice de W. J. Eccles, à Ruette d'Auteuil, DBC. I: 598-599.

29 JDCS, I : 278-280. 
frères avait été un peu trop obstinée, c'est que Jean de La Ferté, avec D'Auteuil, ne fera plus partie du Conseil restauré par le marquis de Tracy, alors que ses collègues y seront. Ce qui est certain, c'est que la conduite de Mésy a été jugée abusive par le même marquis de Tracy, parce que le procès-verbal de cet incident, rédigé ou dicté par le gouverneur lui-même, a été bâtonné et radié dans les registres du Conseil, en signe de condamnation ${ }^{30}$.

Le 24 septembre, le gouverneur réunit de nouveau ce qui restait du Conseil et envoya l'huissier Levasseur convoquer Mgr de Laval. Celui-ci n'était pas encore relevé de sa maladie; il s'excusa. Mésy prit alors sur lui seul de reconstituer le Conseil. En plus de Charles Le Gardeur de Tilly et de Mathieu Damours, anciens conseillers, il nomma

Simon Denys de Vitré,

Jacques Cailhaut de la Tesserie, Louis Péronne de Mazé.

$\mathrm{Au}$ lieu de Jean Bourdon, il établit Louis-Théandre Chartier de Lotbinière comme procureur du Roi et il remplaça aussi JeanBaptiste Peuvret de Mesnu par Michel Fillion comme greffier et secrétaire du Conseil. Evidemment, ces nominations étaient illégales, puisque Mgr de Laval n'y avait pas participé, selon l'exigence de l'édit d'institution. Aussi, le prélat protesta en chaire contre l'initiative du gouverneur et il s'abstint entièrement de paraître au Conseil jusqu'à l'arrivée du marquis de Tracy.

On sait que Mésy tomba malade dans les premiers mois de 1665. Il se réconcilia avec Mgr de Laval, qui l'assista jusqu'à ses derniers moments. Il laissa une lettre au marquis de Tracy, du 26 avril 1665, où il abandonna sa cause au jugement du lieutenant du Roi: "Je ne sais néanmoins, disait-il en parlant des accusations multipliées contre Mgr de Laval et les jésuites, si je ne me serais point trompé en me laissant un peu trop légèrement persuader au rapport qu'on m'en avait fait. Je remets toutefois à votre prudence et aux bons examens que vous en ferez la définition de cette affaire." 31 M. de Mésy mourut le 5 mai.

30 JDCS, I: 278; Roy, Ordonnances, Commissions ..., I: 31-32.

31 [Faillon], Histoire de la Colonie française (3 vol., Ville-Marie, 1865-1866), III: 101; Ferland, Cours d'histoire du Canada (2 vol., Québec, 1861-1865), II: 33; Gosselin, Vie de Mgr de Laval, I: 449; Rochemonteix, Les Jésuites et la Nouvelle-France au 17e siècle, II: 340. 
Son dossier était lourd. Le marquis de Tracy, de concert avec Courcelle et Talon, aussi avec l'approbation de Colbert, jugea qu'il était mieux de laisser dormir sa mémoire. Il persuada l'évêque et les jésuites ${ }^{32}$ de retirer les requêtes qu'ils avaient faites pour obtenir justice de tout ce que le gouverneur avait dit contre eux. Et le dossier fut fermé. Je ne sais s'il en aurait été de même, s'il avait été facile de prouver qu'il y avait eu conspiration ecclésiastique pour dominer le gouvernement du pays, ou du moins si l'on avait trouvé là quelque apparence de vérité.

Mésy est le fonctionnaire métropolitain transplanté dans une colonie minuscule aux mœurs patriarcales. Trente années de pauvreté et de dangers supportés en commun, de liens de parenté tissés par les mariages sans distinction de castes, l'entr'aide mutuelle et la familiarité villageoise avaient forgé une âme et un tempérament à cette collectivité. Elle ne s'accommoderait pas facilement des cadres rigides et compliqués de la bureaucratie européenne. Le Conseil, sorti de cette société, était en consonance avec elle; mais le gouverneur n'a pas eu la patience d'éduquer la population à une vie civile plus raffinée, dont elle ne sentait pas encore le besoin. En outre, Mésy semble avoir été excité par certains personnages, nouveaux venus comme lui: Péronne de Mazé, qui avait le cœur lourd de la mort tragique de son frère et des avanies que son père avait méritées par son zèle indiscret et outrancier, et Cailhaut de La Tesserie, son associé.

\section{Le marquis de Tracy}

Jacques Le Neuf de La Poterie avait été désigné par le défunt pour prendre sa place en attendant un successeur. Mais lorsqu'il se présenta, le 27 mai 1665, pour prendre la présidence du Conseil, les conseillers voulurent bien reconnaître son autorité sur la colonie, mais non la qualité de chef du Conseil, qu'aucune disposition de l'édit ne permettait de déléguer. Le marquis de Tracy, arrivé avant Courcelle et Talon, réunit le Conseil de Mésy, le 6 juillet 1665, pour y faire enregistrer ses commissions et les lettres patentes de la Compagnie des Indes ${ }^{33}$. Mgr de Laval n'y assista pas. Ce fut la dernière séance de ce Conseil. Et le 23

32 Les accusations de Mésy contre les Jésuites étaient graves et méchantes (Rochemonteix, Les Jésuites et la Nouvelle-France au $1^{\text {te e }}$ siècle, II: 528-530; Roy, Ordonnances, Commissions ..., I: 28-31). Elles seront l'arsenal où Colbert, Frontenac, Le Clercq, Le Tac puiseront leur mitraille. Colbert fut bien d'avis d'oublier la mémoire de Mésy, mais lui-même n'oublia jamais les accusations du gouverneur.

33 JDCS, I: 363-364. 
septembre 1665, après l'arrivée du gouverneur et de l'intendant, c'est l'ancien Conseil qui fut réuni, pour l'enregistrement des commissions des nouveaux venus ${ }^{34}$. Voici la liste des membres présents par ordre de préséance:

Alexandre de Prouville, marquis de Tracy,

Daniel de Rémy, sieur de Courcelle,

François de Laval, évêque de Pétrée et nommé au siège de Québec,

Jean Talon,

Claude Le Barrois, agent général de la Compagnie

(qui avait séance avant le $1^{\text {er }}$ conseiller),

Louis Rouer, sieur de Villeray,

Jean Juchereau, sieur de La Ferté,

Denis-Joseph Ruette, sieur d'Auteuil,

Charles Le Gardeur, sieur de Tilly,

Mathieu Damours, sieur des Chauffours,

Jean Bourdon, sieur de Saint-Jean, procureur du Roi,

Jean-Baptiste Peuvret de Mesnu, greffier.

Donc aucun des conseillers nommés par Mésy, mais tous ceux qui avaient été établis en 1663 . Le Conseil ne devait se réunir que plus d'un an plus tard, le 6 décembre $1666^{35}$. Cette fois, ce fut pour installer le Conseil restauré, dont voici les membres, encore par ordre de préséance:

Le marquis de Tracy,

Daniel de Rémy, sieur de Courcelle,

Jean Talon, intendant,

Mgr de Laval,

Louis Rouer de Villeray,

Pierre de Gorribon (ci-devant conseiller au présidial de Maresmes),

Charles Le Gardeur de Tilly,

Mathieu Damours,

Jacques Cailhaut de La Tesserie,

Jean Bourdon, procureur,

Jean-Baptiste Peuvret de Mesnu, secrétaire-greffier.

Comme on le voit, Juchereau de La Ferté et D'Auteuil avaient été mis de côté, peut-être à cause de leur rôle dans la prestation du serment du syndic. D'autre part, tous les conseillers de Mésy avaient été négligés, à l'exception de Jacques Cailhaut de La Tesserie. Villeray, Bourdon et Peuvret étaient restaurés

34 JDCS, I : 364-366.

35 JDCS, I: 366-367. 
honorablement. Mais il y a à remarquer que Mgr de Laval a baissé d'un rang, dans l'ordre de préséance. C'est sûrement à l'instance de Talon, qui ne pouvait souffrir d'être précédé de l'évêque. Cependant, cela était irrégulier : il allait de soi que le lieutenant du Roi passât avant l'évêque; mais l'ordre du Clergé avait préséance sur tous les autres, après le Roi. Mgr de Laval, normalement, devait passer avant Talon, qui n'était qu'un magistrat. Colbert et Talon le savaient bien, qui rétablissaient subtilement, dans un rapport de 1669 à mettre sous les yeux du Roi, l'ordre de préséance tel qu'il aurait dû être conservé, mais qu'on n'observait pas à Québec ${ }^{36}$. On ne voit cependant pas que Mgr de Laval ait fait la moindre protestation devant cet arrangement du marquis de Tracy.

On sait que le séjour du marquis de Tracy à Québec fut en somme favorable à l'autorité de Mgr de Laval, beaucoup trop au gré de Jean Talon ${ }^{37}$. L'autorité du marquis, supérieure à celle du gouverneur, empêcha les heurts jusqu'à son départ, en septembre 1667. Après ce départ, le gouverneur prit la première place qui lui revenait par son office, l'intendant ayant droit de le remplacer en son absence. Le Conseil était avant tout une cour de justice et le roi avait confié la présidence effective de cette cour, non pas au gouverneur, mais à l'intendant, qui avait aussi pouvoir de juger seul en matière civile les causes qu'il croirait à propos. En conséquence, le Conseil lui donna le droit de trier les causes et de décider lesquelles iraient au Conseil, ou au lieutenant civil, ou à lui-même. Le but était de rendre une justice plus expéditive et moins coûteuse, vu la pauvreté de la colonie; mais c'était un droit dangereux, dont Talon ne paraît pas avoir abusé toutefois. Courcelle protestera constamment contre ce pouvoir, qui lui paraissait une diminution de l'autorité du gouverneur ${ }^{38}$.

\section{La permission de la traite d'eau-de-vie}

Mgr de Laval assistait régulièrement aux séances, avec quelques absences où il ne se faisait plus remplacer par l'un de ses vicaires généraux. A l'arrivée de Claude de Bouteroue, en 1668, celui-ci prit sa place d'intendant ${ }^{39}$, ayant préséance sur l'évêque. Le 10 novembre de cette année ${ }^{40}$, le Conseil, où Jean

36 "Un Conseil souverain composé de Mr Le Gouverneur Président M. Lévesque de Petrée M. de Boutrou Intendant..." ("1669. L'Etat du Canada en général", RAPQ (1930-1931): 109).

37 Talon à Colbert, 26 août 1667, RAPQ (1930-1931) : 76.

38 JDCS, I : 448.

39 Le 22 octobre 1668 (JDCS, I: 521 ).

40 JDCS, I : 534-536. 
Talon assistait pour la dernière fois, édicta cette fameuse permission de vendre de l'eau-de-vie aux indigènes. Mgr de Laval refusa de signer cet arrêt, de même que le conseiller Le Gardeur de Tilly; mais Villeray, qu'on fera si souvent passer pour l'affidé de l'évêque et un jésuite en culotte, le signa avec les autres.

Cet incident démontre que le Conseil pouvait être manipulé de très haut. Nous n'avons pas à nous étendre ici sur les effets désastreux de la vente d'eau-de-vie aux indigènes. Ils posaient un grave problème moral aux ecclésiastiques et une non moins lourde charge aux responsables de l'ordre public. On pouvait s'attendre à une étroite collaboration des deux pouvoirs pour réprimer ce mal. En fait, cette collaboration avait été à peu près constante depuis 1633. Les ordonnances successives, appuyées de sanctions toujours plus sévères, avaient interdit ce commerce. Elles avaient été couronnées par un arrêt royal du 5 mars 1657, interdisant ce trafic d'eau-de-vie sous peine de punitions corporelles graves. En 1659, le contrat de la Communauté avec la compagnie Rozée et Guenet ayant provoqué une concurrence effrénée dans la poursuite des castors, le fléau empira et le jeune vicaire apostolique crut devoir renforcer les interdictions civiles d'une peine d'excommunication, décrétée le 5 mai $1660^{41}$. D'Argenson, le gouverneur, en fut humilié. Peu après l'arrivée du successeur, D'Avaugour, Mgr de Laval suspendit son décret, en octobre 1661. Mais le gouverneur ayant cessé dans un mouvement d'humeur d'appliquer l'arrêt royal et les ordonnances, le prélat rétablit son excommunication, le 24 février $1662^{42}$. Durant l'hiver suivant, que l'évêque passa en France, Louis XIV lui donna raison, mais la peine ecclésiastique dut paraître excessive aux métropolitains. A partir de ce moment, il n'en sera plus question pour ce sujet dans l'église canadienne.

A peine établi, le Conseil souverain renouvelle l'interdiction de la vente de l'eau-de-vie aux indigènes. le 28 septembre 1663, conformément à l'arrêt royal de 1657, toujours en vigueur ${ }^{43}$. Même durant ses démêlés avec Mgr de Laval, Mésy, avec le Conseil, montra du zèle à poursuivre les coupables, comme les registres en font foi ${ }^{44}$. Et le jour même où le marquis de Tracy installa le Conseil renouvelé, le 5 janvier 1667 , la première mesure qu'il lui fit prendre fut encore une prohibition de ce

41 Têtu et Gagnon, Mandements, Lettres pastorales et Circulaires des Evêques de Québec (Québec, 1887), I: 14-15.

42 Têtu et Gagnon, Mandements ... ., I: 42-43.

43 JDCS, I : 8-9.

44 JDCS, I : 64, 129, 170-171, 188, 340-341. 
commerce, à laquelle Jean Talon fut obligé de prêter son concours. Et il dut y participer de nouveau, aussi tard que le 29 février $1668^{45}$.

Car l'intendant aurait bien désiré autre chose ${ }^{46}$. Son maître, Colbert, à partir d'une conception tout abstraite du gouvernement colonial et avec la logique cartésienne qui l'a inspiré plus d'une fois en politique, avait pris le parti de dénier tout caractère moral au problème. C'était uniquement une affaire de police. Et comme il était désireux de faire payer à Mgr de Laval le rappel du gouverneur D'Avaugour, il entendait la résoudre de manière à faire sentir à l'évêque le poids de l'autorité d'un officier royal. Il insistait pour que le Conseil souverain se chargeât seul de permettre le commerce de l'eau-de-vie. Jean Talon sentait bien qu'il y avait une difficulté légale ${ }^{47}$. Un arrêt du Roi ne peut être révoqué que par le Roi. Et il demandait quelle était la volonté royale sur ce point. Mais Colbert refusait de porter cette question devant Louis XIV, qui aurait demandé une enquête et consulté les ecclésiastiques ${ }^{48}$. Attitude louche chez un ministre de Louis XIV; mais on aura d'autres exemples du despotisme de Colbert en Nouvelle-France, considérée par lui comme un champ d'expérience privilégié pour l'application de ses idées politiques.

C'est ainsi qu'en 1668, un nouvel intendant, Claude de Bouteroue, est envoyé au Canada. Dans les instructions officielles qu'il lui donne, le ministre lui recommande d'enquêter sur les avantages et les inconvénients de la traite de l'eau-de-vie aux Indiens et d'en faire rapport au Roi, pour un examen approfondi de la question ${ }^{49}$. Mais dix-huit jours seulement après avoir pris possession de son office, c'est-à-dire le 10 novembre 1668, Bouteroue, en présence de Courcelle, de Jean Talon et de Mgr de Laval, faisait adopter par la grande majorité du Conseil une résolution permettant sans aucune réserve la vente de l'eau-de-vie aux indigènes. La mesure dérogeait manifestement aux instructions officielles reçues par l'intendant et contrevenait à un arrêt royal jamais révoqué. Comment le gouverneur, l'ancien intendant, les conseillers, et Bouteroue lui-même, auraient-ils pu agir ainsi, s'ils n'y avaient été poussés par un ordre secret, mais précis et urgent, de Colbert? Le ministre mettait le Roi devant un fait accompli.

45 JDCS, I : 368-369, 474-475.

46 Talon à Colbert, Québec, 13 novembre 1666, RAPQ (1930-1931) : 58.

47 Talon à Colbert, Québec, 29 octobre 1667, RAPQ (1930-1931) : 88.

48 Colbert à Talon, 20 février 1669, RAPQ (1930-1931) : 97.

49 Pierre Clément, Lettres, instructions et mémoires de Colbert (8 vol., Paris, 1861-1882), II' : 404-405. 
L'arrêt du Conseil était-il au moins motivé par un avantage économique considérable? Cet argument n'y est invoqué d'aucune facon. Aussi bien, la concurrence des colonies voisines n'imposait pas cette mesure à ce moment, car elle ne jouait pas encore. Ce qui est mis de l'avant est une préconception de Colbert: pour franciser les Indiens, il faut les traiter à tous égards comme des Français, les soumettre aux mêmes lois et aux mêmes châtiments et leur accorder les mêmes libertés, dont celle de boire. L'eau-devie, selon l'arrêt du Conseil, est un instrument de civilisation: "Et ayant mis en considération tous les moyens (d'empêcher les désordres) ... n'en trouvant point de plus convenable que celuy d'admettre la liberté aux dicts sauvages d'en user à l'instar des François, afin de les introduire par là dans la société et commerce des plus honnestes gens ..." ${ }^{50}$. L'eau-de-vie civilisatrice, plaisante chose!

\section{Laval mis au rancart}

Jean Bourdon, procureur général, étant mort le 12 janvier 1668, Michel Fillion, l'ancien greffier établi par Mésy, fut nommé substitut pour tenir sa place. Le 14 janvier 1669, le gouverneur de Courcelle, l'intendant Bouteroue et $\mathrm{Mgr}$ de Laval réorganisèrent le Conseil ${ }^{51}$. En fait, le seul changement consista à nommer Nicolas de Mouchy substitut du procureur à la place de Michel Fillion. Et à partir de ce moment, on prendra l'habitude de faire annuellement la nomination des conseillers, comme l'édit d'institution en donnait le pouvoir. On voit que l'intendant s'était donné un rôle dans cette nomination, alors qu'il n'en avait aucun de prévu. Tout cela n'était sans doute pas sans intention. Car l'année suivante, on allait prendre des initiatives un peu plus audacieuses. Durant l'année 1669, Mgr de Laval ne parut que peu de fois aux séances du Conseil. Le 13 janvier 1670, il était malade, quand le gouverneur Courcelle et l'intendant Bouteroue convoquèrent au château Saint-Louis ceux qu'ils voulaient nommer au Conseil. On laissait tomber Rouer de Villeray, et Pierre de Gorribon était décédé à l'Hôtel-Dieu à l'automne de 1669 52, Nicolas du Pont de Neuville et Nicolas de Mouchy devenaient conseillers, les autres, Tilly, Damours et la Tesserie étant continués dans leur office et remontant de deux rangs. René-Louis Chartier de Lotbinière, fils de Louis-Théandre, devenait substitut

50 JDCS, I : 535.

51 JDCS, I : 539-540.

52 Albert Jamet, Annales de l'Hôtel-Dieu de Québec (Montréal, 1939), 163. De Gorribon mourut après le 26 août 1669 . 
du procureur et Peuvret de Mesnu demeurait greffier ${ }^{53}$. La destitution de Villeray et la nomination des autres n'avaient pas été faites d'accord avec Mgr de Laval. Jean Talon s'en rendit compte, à son retour, car son secrétaire, Jean-Baptiste Patoulet, écrivit au ministre demandant qu'il fût remédié à ce vice de forme, au moins pour cette fois, par un arrêt du Roi. Peu à peu, on tâchait de mettre la main sur le Conseil. Or Mgr de Laval ne protesta pas contre cette atteinte à ses droits; il jugeait sans doute que le silence était moins dommageable. Aussi, en avril 1670, revenu à la santé, il recommença à paraître au Conseil, siégeant avec les nouveaux élus. Il était présent, le 12 janvier 1671, lorsque tous ces membres du Conseil furent nommés de nouveau et il $\mathrm{y}$ donna son consentement ${ }^{54}$.

Ainsi, les hommes de Colbert fortifiaient peu à peu leur emprise sur les institutions, sans trop tenir compte des décisions royales. Courcelle continua seul les mêmes conseillers, le 28 mars 1672, Jean Talon étant malade et l'évêque étant en France. Le gouverneur ne pensa pas à inviter le premier ecclésiastique du pays, M. de Bernières, selon les dispositions de l'édit. Mgr de Laval était encore absent, le 16 janvier 1673, lorsque "haut et puissant Seigneur, etc. etc.", Louis de Buade-Frontenac, gratifia son Conseil d'un discours qu'il fit inscrire dans le registre, à l'occasion du renouvellement du mandat des conseillers. Il les accablait de sa condescendance et leur disait, entre autres choses: “...j'ay cru ne devoir aporter cette année d'autre changement dans le Conseil Souverain que celuy de remplir la charge qui y estoit vacante d'une personne qui, se conformant sur vos exemples, essayera sans doute à ne pas donner lieu de me repentir de l'avoir choisie pour l'occuper" ${ }^{55}$. Ce nouveau conseiller, mis à la place de Nicolas de Mouchy retourné en France ${ }^{56}$, fut JeanBaptiste de Peiras, qui suivra servilement tous les caprices de Frontenac. Jacques Cailhaut de la Tesserie étant mort ${ }^{57}$ dans le cours de l'année 1673, Frontenac le remplaça, toujours de sa seule autorité, le 21 août 1673, par Charles Denys, sieur de

53 JDCS, I: 590-591. Le procès-verbal dit que les nominations ont été faites du consentement de Mgr de Laval. Une lettre du secrétaire de Jean Talon à Colbert montre le contraire. L'intendant n'approuve pas la destitution de Villeray et il craint que l'on conteste la conduite du gouverneur, demandant qu'elle soit ratifiée par un arrêt royal, pour cette fois (P.-G. Roy, "Rouer de Villeray", BRH, 26 (1920) : 46-47).

54 JDCS, I : 643.

55 JDCS, I: 707-708.

56 Après le 31 octobre 1672.

57 Il fut inhumé dans l'église de Québec, le 17 juin 1673. 
Vitré ${ }^{58}$. Sans intendant pour faire contrepoids et avec la bénédiction de Colbert, Frontenac dominait tout. Il représentait le pouvoir exécutif et le pouvoir militaire. Il était devenu le président du tribunal suprême, commandant un collège formé en partie de ses créatures et en partie de conseillers qui, bien qu'honnêtes, étaient peu instruits dans le droit et ne se souciaient pas d'affronter le despote en résistant à sa volonté. En outre, le gouverneur avait repris à son profit la pratique de Jean Talon de garder à lui seul les causes qu'il jugeait bon de réserver. Comme il n'avait pas la conscience professionnelle de l'ancien intendant, il en profitait pour désavantager ses adversaires et protéger ses amis, non moins que pour assouvir ses mesquines vengeances. On ne trouvait plus en Nouvelle-France les garanties d'équité auxquelles les institutions françaises étaient parvenues après des siècles d'expérience. Il était même difficile d'en appeler au Roi, car Frontenac, sous des prétextes futiles, empêchait parfois un appelant de traverser l'Atlantique. Le désordre, si contraire aux volontés royales, qui s'établit sous ce régime dans la vie commerciale et sociale apparaissait encore dans l'appareil politico-judiciaire. Et cela, parce que Louis XIV avait trop abandonné la Nouvelle-France à Colbert et à ses satellites.

\section{Les déboires de Frontenac}

Tout allait pour le mieux dans le meilleur des mondes pour Frontenac, qui avait désormais un Conseil bien docile. Aussi, le 15 janvier 1674, il fit son discours annuel, qui fut encore copié sur le registre, et ne jugea à propos de changer aucun des conseillers ${ }^{59}$. Il pouvait se montrer bon prince. Le 13 novembre précédent, il avait écrit à Colbert: "Il n'y a qu'une chose qui nous embarrasse souvent, qui est que n'y ayant que cinq conseillers, on est nécessité, dès qu'il survient une affaire criminelle, d'appeler des étrangers, ce qui n'arriverait point si vous jugiez à propos d'en augmenter le nombre jusqu'à sept." 60 Avoir deux nouveaux conseillers à sa nomination, c'était pour Frontenac un beau moyen d'établir définitivement son pouvoir sur le Conseil, qui aurait compté quatre de ses créatures sur sept.

Mgr de Laval était toujours en France. Colbert ne le prisait guère. Mais le prélat pouvait parler aux chefs de la Compagnie des Indes, qui s'étaient trop peu souciés de l'administration canadienne jusque-là. La réponse de Colbert à la lettre de Frontenac

58 JDCS, I : 763.

59 JDCS, I: 786-787.

60 Frontenac à Colbert, 13 novembre 1673, RAPQ (1926-1927) : 30. 
fut une surprise pour le gouverneur. Sur présentation de la Compagnie, deux conseillers étaient nommés par le Roi, ainsi qu'un procureur. Frontenac recevait l'ordre de réintégrer Rouer de Villeray à sa première place au Conseil, comme s'il n'en était jamais sorti. René-Louis Chartier de Lotbinière, substitut du procureur, était élevé au rang de conseiller et Denis-Joseph Ruette d'Auteuil, ancien membre du Conseil mis de côté par M. de Tracy, succédait à Jean Bourdon comme procureur ${ }^{61}$. Villeray était réinstallé par autorité royale, malgré les persécutions et les accusations de Frontenac contre lui. Il est vrai que le Conseil, pour faire plaisir à Frontenac, prit prétexte de ce que Villeray n'avait pas reçu ses lettres de provision pour l'admettre sans indiquer son rang, en attendant les ordres du Roi ${ }^{62}$. En conséquence, Villeray évita de paraître au Conseil en qualité de conseiller jusqu'au 23 septembre 1675, date de l'enregistrement de ses lettres ${ }^{63}$. Chartier de Lotbinière était aussi nommé par le Roi, alors que les anciens conseillers ne l'étaient pas. Il exigea d'avoir rang avant eux. On refusa de le lui accorder, en attendant des instructions ${ }^{64}$. Enfin, Villeray, Lotbinière et D'Auteuil échappaient désormais à la nomination et à la destitution de Frontenac, et donc au chantage qu'il ne se gênait pas de pratiquer. Les autres conseillers, privés de cette assurance, demandèrent au gouverneur de leur obtenir à tous des provisions royales. Elles viendraient l'année suivante, mais sous une forme qui ne fut pas agréable à Frontenac. Celui-ci ne prisa guère les changements faits par le Roi, surtout en ce qui concernait Villeray. Non seulement les lettres de provision du conseiller se perdirent mystérieusement et sans remède, mais le gouverneur le desservit encore longuement dans sa lettre à Colbert du 14 novembre $1674{ }^{65}$. Il terminait: "Ce qu'il y a de certain et que je suis obligé de vous mander, afin que vous puissiez en être éclairci par des personnes dignes de foi et désintéressées, si je suis si malheureux que vous n'ayez pas de créance à ce que je vous en écris, est qu'il vaudrait autant avoir mis dans le Conseil

61 Mort en janvier 1668 et jamais remplacé.

62 JDCS, I: 859-861. Cette entrée, signée par Frontenac, exhale l'hypocrisie. Les lettres de provision de Villeray furent expédiées en chancellerie, probablement le 28 ou le 29 mai 1674 , comme celles de Chartier de Lotbinière et de Ruette d'Auteuil. Mais elles se perdirent, soit en France, soit au Canada. Si Frontenac ne les a pas subtilisées, cette perte faisait bien son affaire, puisqu'il essaya de faire révoquer la nomination. Les lettres que seront enregistrées en 1675 porteront la date du 26 avril 1675 .

63 JDCS, I : 989.

64 JDCS, I: 856-857.

65 Frontenac à Colbert, 14 novembre 1674, RAPQ (1926-1927) : 63-65. 
le Père supérieur des Pères Jésuites et le Père ministre que les sieurs de Villeray et D'Auteuil." 66

\section{Les procès Perrot et Fénelon}

Mais l'affaire échappait désormais au protecteur de Frontenac. L'ordre de réinstaller Villeray arrivait au beau milieu des procès de François-Marie Perrot, gouverneur de Montréal, et de Francois de Salignac-Fénelon, sulpicien. Perrot, neveu de Jean Talon par sa femme, avait demandé le gouvernement de Montréal dans l'intention de s'enrichir. Il ne se gênait pas pour protéger les coureurs de bois. En 1673, il emprisonna un envoyé de Frontenac, qui résolut de se venger. Le gouverneur le fit venir par ruse à Québec, accompagné de $\mathrm{M}$. de Fénelon, ayant promis à ce dernier de ne faire aucune violence à Perrot. Mais la parole de Frontenac n'avait pas de valeur; Perrot fut jeté en prison et mis en accusation devant le Conseil souverain. L'accusé récusa ses juges, parce qu'il avait été nommé par le Roi. Il récusa spécialement les conseillers nommés par Frontenac, Peiras et Vitré. Villeray et D'Auteuil, qui n'étaient pas encore au Conseil, furent appelés comme juges surnuméraires. Mais Villeray se récusa lui-même, flairant avec raison un piège de Frontenac. Il avait aidé Perrot à dresser sa défense et se trouvait le plus habile conseiller des victimes du gouverneur. Perrot, en tout cas, se défendit si bien que le Conseil dut le renvoyer au Roi, au grand déplaisir de Frontenac ${ }^{67}$.

M. de Fénelon, outré du manque de parole du gouverneur, fit le sermon de Pâques 1674 sur les abus d'autorité des magistrats. La Salle l'entendit et il en avertit aussitôt Frontenac. M. de Fénelon fut sommé de présenter son sermon au Conseil, d'y comparaître lui-même; les sulpiciens y furent appelés comme témoins; les prêtres de l'évêché également. Tous récusèrent la compétence du Conseil. Car la cause d'un prêtre devait d'abord passer devant l'officialité du diocèse, laquelle avait à juger si le cas demandait que l'évêque remît l'accusé au bras séculier. Le Conseil n'avait pas le droit de s'en saisir immédiatement. A l'instigation de Frontenac, il prit le parti stupide de nier la juridiction de l'officialité, établie par Mgr de Laval dès 1659, bien qu'elle ne semble pas avoir eu l'occasion d'agir avant 1674 . La récusation de Fénelon força quand même le Conseil à renvoyer

66 Ibid., 65.

67 JDCS, I: 790-792, 793-794, 805-807, 808, 829-830, 830-831, 837-838, 845-847, 868-869, 878-879. 
la cause au Roi. Les deux accusés passèrent en France en novembre $1674{ }^{68}$.

Cependant, le procès de Fénelon eut une conséquence que n'avait pas prévue Frontenac. L'accusé ayant exigé d'être renvoyé au tribunal de l'évêque, le Conseil fut obligé de s'informer de ce qu'était ce tribunal et de ses fondements juridiques. Il assigna donc le grand vicaire, $M$. Henri de Bernières. A la séance du 23 août $1674{ }^{69}$, le greffier fut envoyé au séminaire pour le chercher, en lui donnant l'assurance qu'on aurait pour lui tout l'égard habituel des cours de France pour les ecclésiastiques. M. de Bernières, refusant de discuter avec Peuvret de Mesnu sur la place qui lui serait donnée au Conseil, l'assura qu'il fournirait les explications demandées, mais ne voulut pas se rendre à l'assemblée. Deuxième voyage du greffier; deuxième refus. Le Conseil dressa alors un arrêt lui commandant de venir. Le grand vicaire s'exécuta dans l'après-midi. A son arrivée, on le pria de s'asseoir à côté du substitut du procureur général, en gardant son chapeau sur la tête. Dans l'esprit du Conseil, on lui faisait honneur. Mais $M$. de Bernières refusa, disant que sa place, en l'absence de l'évêque, était celle même de Mgr de Laval, à côté du gouverneur, selon l'édit de fondation du Conseil. On lui répondit que cela n'avait pas eu lieu depuis la réforme du Conseil par M. de Tracy (réforme qui n'avait rien changé aux dispositions de l'édit royal). Comme on ne voulut pas lui donner la place requise, $M$. de Bernières se retira. Le Conseil délibéra, refusa de céder et résolut d'attendre des instructions du Roi sur ce point. Il assigna de nouveau $M$. de Bernières pour le lundi suivant. Le 27 août, le grand vicaire protesta contre la résolution du Conseil, puisque sa place était clairement indiquée dans l'édit; le Conseil s'obstina. $\mathrm{Au}$ cours de la discussion,

Monsieur le Gouverneur s'estant enquis de lui en plein Conseil pour quelle raison il n'avoit point demandé jusques à présent d'entrer dans le Conseil, puisqu'il en avoit la prétention, il avoit répondu qu'il a suivy en cela la conduicte du dict sieur Evesque, lequel, pendant un temps assez considérable, ne s'y est point trouvé, pour quelques raisons, qu'auparavant il ne fust invité à y aller; et qu'il n'a eu garde de le demander, n'en ayant esté requis et ayant voulu suivre son exemple ${ }^{70}$.

68 JDCS, I: 809-810, 812, 817-819, 819-821, 822-823, 823-824, 826-828, $832-833,833-834,835-836,841,841-844,845,849-850,854,862-863,866-867$, $869,870-871,877-878$.

69 JDCS, I: $820-823$.

70 JDCS, I : 825. 
Cette explication nous reporte au temps du gouverneur de Courcelle. Il semble qu'on ait manqué d'égard à Mgr de Laval, le 10 novembre 1668, jour de la fameuse permission de vendre de l'eau-de-vie. Le vicaire apostolique ne reparut plus au Conseil. Le 14 janvier 1669 , on avait besoin de lui pour renouveler le mandat des conseillers et nommer Nicolas de Mouchy substitut; on l'invita et il s'y rendit ${ }^{71}$. Il fut encore ainsi convoqué le 21 janvier 1669, le 8 avril, le 17 juin, le 19 août, puis le 26 août ${ }^{72}$. Invité encore le 13 janvier 1670, pour le renouvellement des mandats des conseillers, il s'excusa sur la maladie ${ }^{73}$; c'est alors que Villeray fut limogé. J'ai déjà dit que Talon en eut des inquiétudes. On ne revit Mgr de Laval au Conseil que le 14 avril $1670^{74}$. Il y vint ensuite plus fréquemment. Il assista au renouvellement des conseillers, le 12 janvier 1671, approuvant ainsi le Conseil tel qu'il était en 1670 , puisqu'il n'y eut aucun changement ${ }^{75}$. Il parut la dernière fois au Conseil avant son départ pour la France, le 5 octobre $1671^{76}$.

\section{Les préséances à l'église}

Donc, à l'occasion du procès de M. de Fénelon fut posé le problème de la représentation de l'évêque pendant ses absences. Cela n'empêcha pas Frontenac de continuer ses harcèlements contre le clergé; cela l'encouragea plutôt. Louis XIV avait fait un règlement, le 2 mars 1668, par lequel il ordonnait que, dans les cérémonies religieuses, dans les églises et en dehors, les officiers de justice auraient préséance sur les marguilliers, après le gouverneur ou le seigneur ${ }^{77}$. Dans un autre arrêt, du 12 avril 1670 , il avait ordonné de diviser la population en bourgades et

71 JDCS, I : 539-540.

72 JDCS, I : $540,550,556,574,576$.

73 JDCS, I: 591.

74 JDCS, I : 602 .

75 JDCS, I: 643 .

76 JDCS, I: 662 .

77 Edits, Ordonnances royaux..., 65. L'édit avait pour but de débouter les officiers du régiment de Carignan des prétentions qu'ils avaient à une préséance dans les cérémonies religieuses. Il donnait toutefois en général et sans précision aux officiers de justice la préséance sur les marguilliers. C'était le temps où Colbert faisait la pluie et le beau temps dans la colonie. L'édit reflète sa pensée, plutôt que celle de Louis XIV. Les termes sont trop généraux et prêtent aux interprétations excessives. L'arrêt du Conseil allait encore plus loin, car il privait entièrement et à perpétuité les marguilliers de tout signe d'autorité dans leur propre juridiction, en faveur de représentants d'une juridiction entièrement étrangère. Passe que les représentants du Roi aient préséance aux jours solennels, où le Roi participe au culte du peuple, mais pas quotidiennement. 
paroisses et d'accorder quelques honneurs aux principaux habitants, à l'église ou ailleurs ${ }^{78}$. Partant de là, Frontenac s'efforça d'établir un véritable cérémonial, où s'affirmerait, dans les offices religieux, la supériorité des magistrats civils sur les fonctions laïques attachées aux lieux de culte. Le 2 février 1675, à la Chandeleur, il fit acheter pour l'église de Québec des cierges à distribuer selon cet ordre: au gouverneur, au Conseil assistant en corps, au lieutenant général de la Prévôté, avant que les marguilliers fussent servis. Le curé, en même temps vicaire général, ne distribua pas les cierges. Le 4 mars, à l'occasion d'un procès entre le procureur fiscal de Montréal et le marguillier en charge, Jean Aubuchon, le gouverneur donna l'ordre de publier de nouveau les deux ordonnances royales mentionnées ci-dessus, en même temps qu'un arrêt du Conseil déclarant que "les officiers de justice du dit lieu de Montréal, ainsi que de tous les autres lieux de ce paīs auront après les gouverneurs ou seigneurs un banc ou place particulière dans le lieu le plus honorable de chaque église et que lorsqu'ils se trouveront au service divin, tant à jour ordinaire qu'extraordinaire, ils auront doresnavant avant les marguilliers le pain bénict, la paix, encens, quaiste, cierges, ramaux et autres honneurs, tant dedans que dehors l'église de leur lieu ... ${ }^{79}$ " C'était amplifier beaucoup ce que le Roi avait décidé.

Frontenac se proposait surtout de venger l'affront de la Chandeleur. Son arrêt avait provoqué un tollé général, spécialement à Québec où l'huissier Genaple avait choisi le jour de Pâques, 14 avril, pour le signifier. Le Conseil, sur l'ordre de Frontenac, convoqua les marguilliers de la paroisse, qui s'entendirent reprocher de n'avoir pas offert les cierges, d'avoir laissé détourner les aumônes des fidèles par les ecclésiastiques, d'avoir laissé faire par ceux-ci une clôture fermant le terrain de la fabrique, bâtir sur ce terrain, utiliser un cimetière qui s'y trouvait, après exhumation des corps, pour faire un jardin, etc. ${ }^{80}$. C'était une basse attaque contre le séminaire de Mgr de Laval, bâti sur le terrain cédé par la fabrique. Le curé et les marguilliers donnèrent des explications, auxquelles Frontenac répondit d'une façon hautaine, et ils firent opposition à l'arrêt du 4 mars. Le 26 mars, le Conseil étudia l'opposition de la fabrique. Le procureur général, D'Auteuil, qui voyait bien l'ineptie de la préten-

78 Voir l'enregistrement, JDCS, I : 638-639.

79 JDCS, I: 905 . Voir les ordonnances rendues à ce sujet le 12 février et le 18 mars 1675, dans Arrêts et règlements du Conseil supérieur de Québec et Ordonnances et Jugements des Intendants du Canada (Québec, 1855), 57-59.

80 JDCS, I: 909-911. 
tion du gouverneur, exigea de recevoir personnellement les honneurs revendiqués dans l'arrêt chaque fois qu'il irait à l'église, si le lieutenant général de la Prévôté de Québec devait les recevoir pour lui-même; car il remplissait au Conseil le même rôle que ce magistrat à la Prévôté. Il fit également remarquer que l'arrêt du 4 mars accordait aux officiers de justice de Montréal exactement les mêmes honneurs que le Conseil souverain recevait à Québec ${ }^{81}$. En un mot, il démontra que l'arrêt était ridicule. Mais Frontenac n'était guère sensible à cet argument. Il maintint son arrêt et la fabrique de Québec dut en passer par là.

La signification de l'huissier Genaple, le jour de Pâques, eut des suites plus graves à la côte de Lauson, où M. Thomas Morel était missionnaire et Guillaume Couture juge. Le curé, les marguilliers et les habitants empêchèrent l'huissier d'exécuter son mandat et le juge ne put retirer le bénéfice de l'arrêt. Frontenac fit jeter le marguillier Claude Maugue en prison, ce que le Conseil ratifia peu après. Jean-Baptiste de Peiras, l'un des conseillers affidés de Frontenac, fut désigné pour faire l'instruction contre la fabrique. Le curé Morel comparut devant lui, le 22 mai, et récusa la compétence du juge, parce que sa cause, disait-il, se trouvait déjà introduite à l'officialité devant le grand vicaire. Le procureur D'Auteuil était absent du Conseil, le 27 mai, lorsque Peiras fit rapport. Ayant étudié le cas, il fit quelques jours plus tard un plaidoyer favorable aux prétentions des ecclésiastiques. Peiras le menaça de la colère du Conseil, s’il ne changeait son jugement. Frontenac, un peu plus subtil, réduisit la menace à celle de la colère du Roi, parce que D'Auteuil était de nomination royale. La conclusion de cette séance fut que Morel serait cité à comparaître dans trois jours. On donna aussi l'ordre au greffier de l'officialité, Romain Becquet, de communiquer le dossier de l'instruction de Morel. Ce dernier, faisant défaut, fut arrêté et mis en prison. M. de Bernières refusa de livrer les pièces du procès ecclésiastique et Becquet fut jeté dans une étroite cellule. Les procès-verbaux de ces séances, qui sont très explicites, montrent parfaitement de quelle manière Frontenac, avec ses deux acolytes, Peiras et Denys de Vitré, tenait le Conseil à sa merci. Villeray et Lotbinière s'abstenaient de s'y rendre, parce qu'on ne leur donnait pas leur place. Tilly, dégoûté et malade, n'y faisait que de rares apparitions. Du Pont de Neuville s'absentait souvent. Les trois compères, toujours du même avis, n'avaient comme vis-à-vis que deux conseillers honnêtes, mais timides. Finalement, M. Dudouyt, promoteur du

81 JDCS, I: 912-913, 915, 916, 921. 
tribunal ecclésiastique, consentit à porter au Conseil les pièces justificatives de sa juridiction, en même temps que le dossier de Morel, afin de libérer le greffier, qui n'était coupable que d'avoir fait son devoir. Morel sortit de prison, mais Becquet y resta et il y tomba malade ${ }^{82}$. On ne sait comment la tragi-comédie se serait terminée; car l'intendant Jacques Duchesneau et Mgr de Laval arrivèrent sur les entrefaites, avec un édit de réforme du Conseil, ce qui arrêta toute l'affaire. Jamais, dans toute son histoire, le Conseil de Québec n'est tombé aussi bas qu'en cette année 1675, où il était devenu fréquent de voir les accusés récuser le président du tribunal comme partial et les conseillers Peiras et Vitré comme ses âmes damnées. Il ne restait plus de juges en nombre suffisant pour prononcer les sentences.

Ces dernières esclandres avaient été provoquées par les questions de préséance. Voici le jugement que prononcera le Roi sur l'attitude de Frontenac en ce domaine:

Les honneurs qui sont déférez à vostre caractère dans l'église catédralle de Québec sont plus grands que ceux qui sont déférez aux gouverneurs et lieutenans généraux dans les provinces de mon royaume, et ainsy vous vous en devez contenter, et vous devez accommoder ce petit différend avec le sieur évesque de Québec. Lorsque le Conseil souverain est en corps dans les grandes festes et solennelles de l'année, il doit précéder les marguilliers, mais dans les jours ordinaires, comme festes et dimanches, les marguilliers doivent précéder les officiers de justice. Le surplus de ce différend ne mérite pas de décision précise, mais vous devez soigneusement tenir la main à ce que les prières publiques et accoustumées pour moy se fassent dans toutes les églises de la Nouvelle-france ${ }^{83}$.

\section{Réforme du Conseil}

Voici maintenant les principaux effets de l'édit du 5 juin $1675^{84}$, restaurant le Conseil. Il constitue un blâme cinglant pour Frontenac.

1. Mgr de Laval retrouve au Conseil le rang qui lui était donné par l'édit de 1663 et qui lui avait été enlevé par Tracy, sur l'insistance de Jean Talon. Le représentant du Roi, c'était le gouverneur, et à ce titre il devait passer devant l'évêque. Mais ce dernier, exerçant une autorité, devait siéger avant l'inten960-962.

82 JDCS, I: 924, 926, 934, 935, 940-943, 943-944, 946-949, 950-953,

${ }_{83}^{83}$ Le Roi à Frontenac, 15 avril 1676, RAPQ (1926-1927) : 86.

84 Edits, Ordonnances royaux..., 83-84. 
dant, qui n'était qu'une sorte de ministre de la justice, de l'intérieur et des finances. Un ministre n'est pas investi d'autorité, comme l'est un gouverneur ou un évêque: il fait le service de l'autorité.

2. Le gouverneur est membre du Conseil ex officio. Comme lieutenant du Roi, il occupe la place d'honneur. Il représente la puissance et la force du Roi. Mais il est bien entendu qu'il ne peut exercer cette puissance et cette force sur le Conseil, qui tient immédiatement du Roi son pouvoir d'interpréter et d'appliquer la loi. Le gouverneur n'a aucun droit de faire pression sur les conseillers; seulement celui d'avertir le Roi, s'il pense que les conseillers ne font pas leur devoir.

3. La question de la représentation de l'évêque au Conseil est bien précisée. Il aura droit de se faire représenter par son grand vicaire chaque fois qu'il s'absentera du pays, mais non quand il $\mathrm{y}$ sera. Cela donne raison à $\mathrm{M}$. de Bernières et tort à Frontenac. Mgr de Laval ne tenait pas, sans doute, à répéter la pénible expérience qu'il avait faite avec M. de Charny.

4. Tous les conseillers, au nombre de sept, sont nommés par le Roi et à vie. Frontenac n'aura plus le pouvoir de se créer une clique au Conseil, ni de menacer les conseillers de destitution pour les amener à ses vues. Quant à les expulser et à les mettre en accusation, il devra y regarder à deux fois, car le Roi seul est leur juge.

5. Villeray, malgré les efforts de Frontenac, est restauré à sa première place au Conseil; le Roi lui a payé ses émoluments des cinq dernières années, c'est-à-dire depuis 1669, comme s'il avait toujours appartenu à ce corps.

6. Reproche plus mordant encore, Lotbinière est mis avant Peiras et Denys de Vitré, les créatures de Frontenac, aussitôt après les conseillers nommés au temps de Courcelle. Pourtant, Lotbinière était le dernier nommé de tous les conseillers.

7. Dans l'édit de 1675, il est clairement expliqué que l'intendant est le président effectif du Conseil, celui qui dirige les délibérations, prend les avis, tire les conclusions, signe les procèsverbaux, fait les ordonnances du Conseil. Frontenac est chef du Conseil; l'intendant est appelé président. C'est bien le terme employé dans l'édit ${ }^{85}$. Malheureusement, une lettre rédigée au 85 “(L'intendant) aura la troisième place comme président du dit Conseil" (Ibid.). 
nom du Roi par Colbert appelle encore Frontenac chef et président du Conseil ${ }^{86}$. Ce sera la source d'une chicane violente entre Frontenac, qui voudra se faire donner ces titres, et Duchesneau, qui tiendra à être appelé président ${ }^{87}$. On verra encore au Conseil des luttes épiques, où se déploiera à plaisir le caractère procédurier du gouverneur et qui lui vaudront son rappel en 1682 .

\section{L'affaire Rolland}

Une autre affaire mettra Mgr de Laval en cause au Conseil souverain, celle de François Lenoir, dit Rolland ${ }^{88}$. Nous y insistons parce que le cas est ordinairement mal présenté et que Frontenac, sans le laisser voir, a encore profité de cette occasion pour ennuyer Mgr de Laval dans ses rapports avec le Conseil ${ }^{89}$. Ce Rolland était un soldat du régiment de Carignan, licencié en 1667. Etabli à Lachine, où il faisait le commerce des fourrures, il profitait de la protection que Frontenac accordait aux vendeurs d'eau-de-vie aux indigènes. Depuis 1669, l'évêque s'était réservé à lui seul l'absolution de ce péché. Après Pâques de 1676, Lenoir se présenta à son curé, M. Etienne Guyotte, pour se confesser. Le curé lui demanda d'attendre la venue de Mgr de Laval à l'été. Celui-ci donna en effet le pouvoir d'absoudre, mais avertit sans doute le curé de prendre information et de sonder les dispositions du pénitent. Lenoir, s'en étant aperçu, en fut offusqué. Vers la fin de juin, il apprit que le curé allait dévoiler en chaire les noms de ceux qui n'avaient pas fait leurs pâques et se trouvaient de ce fait exclus des cérémonies et de la sépulture ecclésiastiques. Il se rendit à Montréal chez le supérieur des sulpiciens, M. François Lefebvre, qu'il trouva en compagnie de M. Pierre de Caumont, curé de Boucherville. Après information, l'un et l'autre lui refusèrent l'absolution, parce qu' "il traittoit de l'eaude-vie par excez". Le 29 juin, Lenoir traversa donc à Laprairie pour se confesser au P. Jacques Frémin. Le jésuite dut être bien impressionné par ses protestations, car il écrivit à M. Guyotte un billet pour le recommander. Il ne l'avait cependant pas absous

80 .

${ }^{86}$ Le Roi à Frontenac (non signée), 22 avril 1675, RAPQ (1926-1927) :

87 JDCS, II : 279-296.

88 JDCS, II : 97-100, 102-109, 118-119, 121-123, 132-133.

89 Dans cette histoire, il paraît évident que Rolland comptait sur l'appui que Frontenac donnait autrefois aux protagonistes de ce genre de causes. Le gouverneur invoque assez longuement ce cas de Rolland dans la longue tirade écrite en 1677 pour décrier les ecclésiastiques. Il envoya d'ailleurs en France copie des sentences données par l'officialité (Margry, Découvertes et Etablissements, I : 310). 
et l'avait remis à trois mois, le temps de donner des preuves de repentir.

M. Guyotte lut sa liste en chaire, le 5 juillet; le nom de Lenoir s'y trouvait. Celui-ci s'en plaignit à l'intendant Duchesneau, alors à Montréal, et il semble avoir obtenu un sursis du curé. En novembre, il tenta d'avoir une absolution du P. Frémin; mais il appartenait au curé de l'admettre à la communion. Le 21 novembre, il assista à la messe dominicale; on le laissa faire. Le 28, il y retourna. De l'autel, M. Guyotte lui ordonna de sortir. Comme il refusait, le curé demanda aux paroissiens de l'expulser. Le marguillier, Jean Milot, et quelques autres le poussèrent dehors par force. C'est alors que Lenoir, malgré la saison, descendit à Québec trouver Frontenac, croyant bien lui apporter une succulente affaire contre les ecclésiastiques.

Le gouverneur avait subi trop d'humiliations, récemment, pour commettre une imprudence. Il envoya le plaignant à $\mathrm{Du}-$ chesneau, lequel accepta de déposer la plainte au Conseil, ce qui fut fait le 19 décembre. Le tribunal nomma René-Louis Chartier pour aller faire l'instruction à Montréal. Lenoir s'aperçut de son erreur. Il avait cru que le Conseil embrasserait sa cause au nom de la Couronne, prenant toutes les procédures à son compte. Le procès se trouvait au contraire réduit à une poursuite privée de Lenoir contre Guyotte et consorts, les frais à la charge du poursuivant. Son zèle en fut amoindri et, lorsque Chartier fut sur le point de partir pour Montréal, il lui demanda de n'en rien faire, parce qu'il retirait sa plainte. Lui-même retourna à Lachine.

Le dimanche suivant son arrivée, en janvier 1677, M. Guyotte fit dresser par Jean Quenneville un procès-verbal de l'expulsion et il le fit signer à la porte de l'église par les paroissiens après la messe. Le but semble avoir été d'informer en vue d'un rapport à l'officialité sur l'incident. Cette fois, Lenoir se crut assuré de réussir et reprit le chemin de Québec. Le 26 janvier, il logea une seconde requête au Conseil, où il incriminait personnellement Mgr de Laval et insistait pour que le procureur général prît l'enquête à sa charge, parce que l'honneur du Roi était intéressé. La cour se contenta de le renvoyer à l'exécution de l'arrêt du 19 décembre précédent, c'est-à-dire de poursuivre la procédure déjà amorcée. Mgr de Laval, mis en cause, porta plainte contre la fausseté des allégations de Lenoir. Celui-ci dut avouer qu'il avait menti sur deux points importants, invoquant cependant le témoignage du custode des récollets, présent à son 
entrevue avec l'évêque. Le custode fut cité à son tour, mais il refusa de témoigner et le Conseil accepta ses excuses. En conséquence, la cour laissa tomber toute accusation contre le prélat. Une fois encore, le plaignant voulut arrêter la poursuite, mais les conseillers le forcèrent à demeurer partie et exigèrent de lui l'avance des frais que cela pourrait nécessiter. Chartier de Lotbinière pouvait enfin faire le voyage de Montréal, pour y mener l'enquête.

Dans cette ville, M. François Séguenot, sulpicien et substitut du promoteur de l'officialité, continuait l'instruction pour la cour ecclésiastique. Il cita Lenoir à comparaître pour le 11 mars 1677. Profitant de l'occasion d'opposer les deux juridictions, l'inculpé fait un nouveau voyage à Québec, déposant le 30 mars un appel comme d'abus de la citation de l'officialité. Malgré l'opposition du promoteur, à Québec, l'appel fut reçu. Qu'advint-il de toutes ces poursuites? Rien. La requête en réparation de l'expulsion hors de l'église, objet principal du procès, l'appel comme d'abus n'eurent pas de suites ${ }^{90}$. Le silence des registres, sur ces sujets, incite à croire que Lenoir retira finalement ses plaintes.

De toute l'enquête faite par Chartier à Montréal, le Conseil ne retint qu'un détail: le procès-verbal dressé par Jean Quenneville. Celui-ci n'avait pas qualité pour instrumenter ainsi ${ }^{91}$. Il fut condamné à cinq livres d'amende. Lenoir n'était plus en cause, mais bien le procureur général, pour la Couronne. Il fallait donner cette satisfaction à Frontenac, qui avait suivi toute l'affaire avec intérêt, bien qu'avec une discrétion inaccoutumée ${ }^{92}$. Autre satisfaction: le Conseil publiait un arrêt interdisant à $\mathbf{M}$. Guyotte et à tous les curés de publier à l'église rien autre que des avis ecclésiastiques ou des documents officiels envoyés par l'autorité civile.

$90 \mathrm{~A}$ moins qu'on puisse considérer comme une solution de l'appel comme d'abus l'annulation des procédures de l'officialité prononcée par le Conseil, le 30 mars 1677 (JDCS, II: 122). Le Conseil n'avait pas compétence pour empêcher une instruction d'un tribunal qui ne relevait pas de lui. Si l'officialité, qui était dans son droit, avait voulu contester, l'affaire aurait probablement rebondi jusqu'au Roi. Mais la cessation de la cause principale, en réparation de l'expulsion de l'église, faisait aussi tomber l'appel comme d'abus.

91 Il le faisait probablement par mandat spécial de l'officialité. Mais le Conseil n'était pas disposé à reconnaître cette autorisation.

$92 \mathrm{La}$ preuve de l'intérêt de Frontenac est la déclaration signée de lui et inscrite au registre (JDCS, II: 133). Le gouverneur y présente son rôle sous un jour favorable, selon son habitude, mais il est évidemment l'instigateur de la sentence et de l'arrêt. 


\section{Législation sur l'eau-de-vie}

Le 16 octobre 1679, le Conseil enregistrait l'ordonnance royale du 24 mai précédent, par laquelle Louis XIV résolvait enfin le problème de l'eau-de-vie. La solution était celle-ci: il était interdit sous peine d'amendes et de punitions corporelles aux habitants du pays qui auraient permission d'aller à la chasse dans les bois de porter de l'eau-de-vie hors des habitations françaises ${ }^{93}$. Mgr de Laval, alors en France, n'assistait pas à cette séance, mais il était représenté par son vicaire général, M. de Bernières. Comme cette législation va régir toute cette question à l'avenir, il convient d'expliquer ici comment on y est arrivé.

L'arrêt du Conseil du 10 novembre 1668 avait été rédigé avec tant de légèreté et d'irresponsabilité, permettant comme une chose bonne ou indifférente ce qui était en vérité un acte aux conséquences désastreuses, qu'on ne tarda pas à en expérimenter les résultats. Il ne resta à l'évêque d'autre ressource que de réserver à son absolution deux fautes plus fréquentes aux Français à cet égard: le fait d'enivrer les indigènes et l'abus de leurs femmes ou filles. Son mandement fut daté du 21 avril $1669{ }^{94}$. La mesure, n'ayant pas d'effets publics immédiats, mais se trouvant confinée au confessionnal, lui parut moins susceptible de réprobation que l'excommunication. Bouteroue lui-même put apprécier l'efficacité de l'eau-de-vie pour civiliser les Indiens. Le 26 juin 1669, il demandait au Conseil de sévir contre les soldats et les habitants qui, sous prétexte de chasse, allaient porter de l'eau-de-vie dans les bois, enivrant les indigènes, causant d'autres désordres, rendant "les sauvages paresseux à la chasse" et les empêchant "de venir dans les bourgs avec leurs peaux et leur chasse" ${ }^{95}$.

La permission de vendre de l'eau-de-vie était arrivée au plus mauvais moment. L'alcool était la denrée la plus facile et la plus profitable à transporter, à débiter et à falsifier. Par ses effets sur les Indiens, il multipliait les occasions de les tromper et de les spolier. Les moins honnêtes et les plus irresponsables étaient ceux qui l'utilisaient le plus volontiers. Or le licenciement des soldats de Carignan et l'immigration intense des récentes années avaient multiplié le nombre des hommes sans racines et sans responsabilités dans le pays, prêts à tout pour faire rapidement fortune. Bouteroue, en 1669, se plaignait surtout des "soldats volontaires", qui portaient de l'eau-de-vie dans les bois "à

93 JDCS, II : 320.

94 Têtu et Gagnon, Mandements ..., I: 77.

95 JDCS, I : 558-559. 
trente, quarante et cinquante lieues au-devant des sauvages" 96. Et en 1672, ce sont encore les "volontaires" que Louis XIV ordonne à Talon d'empêcher "d'aller à la chasse et à la traite des pelleteries jusque chez les nations sauvages les plus esloignées" ${ }^{97}$. Ils frustraient les habitants de leurs profits légitimes en empêchant les indigènes de venir à la traite dans les bourgs, alors qu'eux-mêmes, n'étant pas établis, n'avaient pas le privilège d'acheter des fourrures. Ils contrecarraient aussi la politique royale, qui était d'augmenter la fréquentation des habitations françaises par les indigènes, en vue de les civiliser. Talon, le 20 octobre 1671, interdit la traite aux engagés et aux soldats célibataires non établis ${ }^{98}$. Et le 5 juin 1672, dans une ordonnance sévère, il défendit aux habitants de porter dans les bois des marchandises et des boissons sans un congé écrit du gouverneur ou de lui ${ }^{99}$.

Les désordres de l'ivresse chez les Indiens vont croître avec la multiplication des coureurs de bois. Muni de la bienheureuse permission de 1668, Frontenac n'aura garde de la laisser lettre morte, l'invoquant et l'affichant en toute occasion. Il sévira aussi contre les coureurs de bois, favorisant d'autre part leurs abus par la multiplication des congés. Louis XIV, averti que "ces permissions causent la désertion des habitans" empêchent les indigènes de porter leurs fourrures aux habitations et même que ceux qui obtiennent ces congés, "vagabonds et libertins", vont vendre leurs fourrures à l'étranger, fait interdiction absolue à tous d'aller à la traite chez les Indiens et il enlève aux gouverneurs et lieutenants généraux le pouvoir d'octroyer de telles permissions. Les peines sont sévères: confiscation des marchandises et 2000 livres d'amende. L'ordonnance est du 15 avril $1676{ }^{100}$. Le Conseil, en conséquence, décida, le 5 octobre suivant, que les seuls lieux de traite seraient Québec, Trois-Rivières et Montréal ${ }^{101}$. On interdit les expéditions de traite, mais non de chasse. Frontenac donna des congés de chasse, comme les premiers qui avaient donné lieu au fléau des coureurs de bois. Le Roi prohiba les congés de chasse, sous les mêmes peines, le 12 mai $1678^{102}$. L'édit était cependant excessif, privant les habitants d'un moyen nécessaire de se procurer leur nourriture. Sur

96 JDCS, I: 558.

97 Louis XIV à Talon, 4 juin 1672 , RAPQ (1930-1931) : 171.

98 P.-G. Roy, Ordonnances, Commissions ... des Gouverneurs et Inten-

dants (Beauceville, 1924), I: 104-105.

99 Ibid., I: 107-109.

100 Edits, Ordonnances royaux ..., 87.

101 JDCS, II : 75-76.

102 Edits, Ordonnances royaux..., 105. 
les représentations du Conseil, les permissions de chasse furent restaurées, mais à une lieue autour des terres défrichées, et seulement du 15 janvier au 15 avril ${ }^{103}$. Ces mesures, bien observées, auraient atténué les effets de la traite de l'eau-de-vie.

Laissé par Colbert sans intendant, Frontenac avait instauré un régime despotique. Le ministre tamisait ses lettres et ne présentait au Roi que ce qui lui paraissait opportun. Jusqu'à 1675, Louis XIV ne paraît pas avoir entendu parler d'eau-de-vie, bien que Mgr de Laval vécût à Paris durant ces années. Frontenac, d'autre part, incitait Colbert à contraindre le prélat d'abroger le péché réservé touchant l'eau-de-vie ${ }^{104}$. Mais enfin, les plaintes venues de Nouvelle-France parvinrent jusqu'au Roi, qui reprit en main l'autorité usurpée par le ministre sur la colonie. La Compagnie des Indes fut supprimée; Colbert reçut l'ordre de faire adresser au monarque toute correspondance officielle de Frontenac; et un intendant fut désigné pour la Nouvelle-France, en même temps que le Conseil souverain était réformé. Tourmenté par Colbert, Mgr de Laval consulta la Sorbonne sur son droit de réserver le péché de la vente d'eau-de-vie ${ }^{105}$. Louis XIV commençait à s'inquiéter de ce problème, puisqu'il donna à Jacques Duchesneau, l'intendant, instruction de faire enquête à ce propos. Mgr de Laval, nouvel évêque de Québec, était obligé de revenir au Canada; mais il envoya en France l'un de ses prêtres, M. Jean Dudouyt, pour défendre sa cause en matière d'eau-devie. Obstiné et tenace, Colbert ne voulait rien admettre des arguments de Dudouyt ${ }^{106}$. Il opposa une consultation des docteurs de Toulouse ${ }^{107}$ à celle de la Sorbonne, fit un dossier abondant des avis de Talon, de Bouteroue et surtout de Frontenac, tous favorables à l'eau-de-vie. Il se fâcha rouge contre Duchesneau, qui osa envoyer un rapport indépendant flétrissant la vente d'alcool aux indigènes. Dans cette lettre particulière, à l'insu de Louis XIV, il incitait même l'intendant à décourager Mgr de Laval de paraître au Conseil souverain ${ }^{108}$.

Mais Louis XIV se préoccupait désormais du problème de l'eau-de-vie. Il décida de consulter les principaux habitants du

103 Edits, Ordonnances royaux ..., 230.

104 Frontenac à Colbert, 13 novembre 1673, RAPQ (1926-1927) : 33.

105 Têtu et Gagnon, Mandements, I: 91-94.

106 Dudouyt à Mgr de Laval, mai 1677, Quebecen, Beatificationis et Canonizationis Ven. Servi Dei Francisci de Montmorency-Laval episcopi Quebecensis ( +1708$)$. Altera Nova Positio super virtutibus ex officio critice disposita (Typis Polyglottis Vaticanis, MCMLVI (Altera Nova Positio), 167-172.

107 Altera Nova Positio, 98-100.

108 Altera Nova Positio, 167. 
pays, donnant ordre au gouverneur et à l'intendant d'en convoquer vingt. La comparution eut lieu le 26 octobre 1678 devant le Conseil assemblé ${ }^{109}$. Le choix favorisait en principe l'opinion de Frontenac; une absence remarquable, celle d'Aubert de La Chesnaye, trop lié à Mgr de Laval. Les officiers du régiment de Carignan restés au pays étaient gagnés à la thèse du gouverneur: Sorel, Berthier, Dugué, Verchères, Saint-Ours. La Salle, adjoint au groupe à la dernière minute, fut le plus verbeux des opinants; on eût cru entendre Frontenac lui-même. Les marchands, Charron, des Coulombiers, Romain, Laprade, étaient de même opinion. D'anciens habitants, Le Gardeur de Repentigny, Robineau de Bécancour et Picoté de Belestre, émettaient un avis favorable, avec de sérieuses réserves, mais Crevier, habitué avec les Abénaquis sur ses terres, n'en faisait aucune. Pézard de La Touche opina dans le sens de la majorité. Cinq seulement bravèrent le courroux du gouverneur qui les observait en s'opposant radicalement à la traite. Ils étaient tous d'anciens habitants, arrivés avant 1660 ou nés au pays: Jacques Leber, Jean Bourdon de Dombourg, Louis Jolliet, Delestre le Wallon, GatineauDuplessis. Le procès-verbal fut porté en France par les conseillers Dupont et De Peiras ${ }^{110}$.

La grande majorité des avis était favorable à la traite de l'eau-de-vie, mais l'aspect moral de la question n'était pas du tout indifférent à Louis XIV. Il laissa le jugement ultime à l'archevêque de Paris, Harlay-Champvallon, et à son confesseur, le P. de la Chaise ${ }^{111}$. Mgr de Laval lui-même put se faire entendre d'eux, car il était passé en France en même temps que les délégués du Conseil pour y défendre son point de vue. Les deux aviseurs ecclésiastiques s'arrêtèrent à l'avis qu'exprime l'ordonnance royale de 1679 . La traite de l'eau-de-vie pourra se faire dans les bourgs, sous les yeux des forces policières. Mais il sera interdit de transporter l'alcool loin des habitations, même quand on aura la permission du gouverneur d'aller à la chasse. Car les congés de traite des fourrures et de chasse plus loin qu'à une lieue des défrichements sont alors rigoureusement interdits. Il était impossible au Roi de faire une défense plus radicale, dans les circonstances; et si la loi était bien appliquée, Mgr de Laval pouvait s'en contenter. Il consentit à suspendre la réserve imposée en 1669

109 JDCS, II : 253-254.

110 JDCS, II: 247-248, 253-254; "Procès-verbal de l'assemblée au chasteau de Saint-Louis ...", Margry, Découvertes et Etablissements des Français ..., I: 405-420.

111 Colbert à Frontenac, 24 mai 1679, RAPQ (1926-1927) : 101. 
sur la faute de vendre ou de donner aux indigènes de l'eau-de-vie en quantité suffisante pour les enivrer.

Le problème de l'eau-de-vie fut le plus important de ceux qui embarrassèrent les rapports de Mgr de Laval avec le Conseil. Pour le reste, l'évêque assiste désormais aux séances avec assiduité, y donnant son avis librement. Lorsqu'il s'absente pour aller en France, en 1678-1679 et en 1684-1688, sa place est tenue sans discussion par le vicaire général. $M$. de Bernières fut reçu au Conseil à la séance du 5 décembre $1678^{112}$. La même chose arriva à M. Ango de Maizerets, le 7 novembre 1684, et à M. de SaintVallier, le 3 août $1685^{113}$. Celui-ci fut reçu sans même son brevet de nomination à l'évêché de Québec, sur la simple recommandation du marquis de Denonville. L'atmosphère avait changé depuis Frontenac.

\section{Conclusion}

Les difficultés de cette époque, entre Mgr de Laval et les autorités civiles, découlent principalement de l'état de la colonie. Dès le début, le fondement économique des établissements du Saint-Laurent fut le commerce des fourrures. Or ce commerce n'en est un que de transit en Nouvelle-France. Le producteur, c'est l'arrière-pays, avec ses chasseurs indigènes, ses forêts et son gibier. Les capitaux investis, l'industrie de la chapellerie, les consommateurs sont en France. En sorte que les gros profits réalisés dans les fourrures sont faits dans la métropole. Les coloniaux n'ont pour leur part que les émoluments de commis et de transporteurs en partie, en tout cas d'intermédiaires. A ce compte, le volume des fourrures manipulées ne justifiait pas l'existence d'une société organiquement constituée sur notre continent: un comptoir eût suffi, comme il suffisait à la Compagnie de la baie d'Hudson. En outre, la charge financière d'une administration coloniale, imposée en entier à ce commerce, le mettait dès l'abord en état d'infériorité et de faiblesse vis-à-vis des concurrents internationaux.

Les rois de France, ayant toujours voulu un peuplement en Nouvelle-France, l'auraient attendu longtemps et en vain des marchands de fourrure. Heureusement, le zèle missionnaire de la contre-réforme française s'offrit pour cette œuvre. Les sommes investies par la Compagnie de la Nouvelle-France et par les organismes religieux n'ont servi qu'en minime partie au commerce

112 JDCS, II : 264.

113 JDCS, II : 964-965 et 1012. 
et il s'en faut de beaucoup que ce dernier les ait jamais remboursées. C'est ce qui donna la petite colonie, déjà bien structurée, que le Roi prit en main en 1663. De telles origines marquent profondément un groupement humain. Et cela devait entrer en ligne de compte pour les nouveaux dirigeants.

Deux facteurs menaçaient d'éparpillement la petite société du Saint-Laurent: le zèle des missionnaires et la cupidité des traitants de fourrure. Le zèle, d'abord, parce qu'il entraînait les apôtres à la poursuite des tribus paiennes, éparses sur le continent. C'est par leur moyen, surtout, que les Français ont connu les nations de l'arrière-pays et qu'ils ont lié des relations commerciales avec eux. Mais le zèle apostolique ne présentait pas un grand danger pour la société laurentienne, n'animant que les prêtres.

La cupidité créa un péril bien plus grand et bien plus général. Les véritables assises économiques d'une société sont le fruit de son travail, c'est-à-dire sa production. Les fourrures étaient la production d'un continent sauvage, non d'une colonie civilisée. Leur manipulation était pleine de hasards et d'incertitudes et fut toujours insuffisante à procurer les besoins de la population. Il importait avant tout d'assurer la production proprement coloniale. C'est ce que Jean Talon comprit et tenta, de trop courtes années. Mais Frontenac, à qui Colbert livra la colonie, ne s'est jamais élevé jusque-là.

Pour arriver à établir cette production, une discipline vigoureuse était nécessaire, afin de garder tous les bras à l'œuvre du développement et pour dompter l'avidité des aventuriers qui couraient à l'envi au-devant des fourrures, enlevant aux colons un revenu d'appoint qui leur était nécessaire. La course dans les bois prit les proportions d'une maladie sociale en 1667-1668. Il n'est pas douteux que la permission de traiter librement de l'eau-de-vie l'aggrava considérablement. Les dix années du premier gouvernement de Frontenac rendirent le mal incurable et il avait déjà commencé à produire sa séquelle inévitable, la contrebande. En sorte que les édits de Louis XIV, y compris celui de 1679 sur l'eau-de-vie, vinrent trop tard. Avec des alternances de laisser-aller et de résistance, le pouvoir royal devra composer avec le mal, jusqu'à ce que les colons aient parcouru, plutôt qu'occupé, tout le continent, depuis le golfe Saint-Laurent jusqu'à celui du Mexique: une possession stratégiquement indéfendable. 
Si l'on pouvait faire quelque chose pour enrayer ces conséquences prévisibles, c'est au début qu'il fallait le faire. Rien n'était plus nécessaire, pour y arriver, qu'une étroite collaboration entre les autorités civiles et religieuses. L'ascendant de l'Eglise sur la population offrait un concours précieux que des hommes politiques sages ne pouvaient pas négliger en un besoin si grave. Mais l'anticléricalisme étroit de Colbert, son inintelligence de la situation coloniale et son manque de prévoyance ont au contraire provoqué une lutte stérile, dont les instigateurs eux-mêmes n'ont guère profité, tandis que l'avenir de la France en Amérique se trouvait compromis. 